\title{
Exploring Refugee Camp Needs: An Empirical Investigation of Maslow's Theory in Za'atari Camp in 2013
}

\author{
El Arbi Bouaiti ${ }^{12}$, Jalal Kessouati ${ }^{2}$, Mohamed Gartoum ${ }^{3}$, Abdelouahed Elbaite ${ }^{4}$, \\ Sifeddine Elkandry ${ }^{5}$, Khalid Sair ${ }^{5}$, Mustapha Mrabet $^{12}$ \\ ${ }^{1}$ Department Of Public Health, Faculty Of Medicine And Pharmacy Of Rabat, Morocco. \\ ${ }^{2}$ Department Of Hygiene And Community Medicine, Mohamed V Military Hospital, Hay Ryad 10100 Rabat, \\ Morocco. \\ ${ }^{3}$ Department Of Psychiatry, Mohamed V Military Hospital, Hay Ryad 10100 Rabat, Morocco. \\ ${ }^{4}$ Department Of Medical Intensive Care, Mohamed V Military Hospital, Hay Ryad 10100 Rabat, Morocco. \\ ${ }^{4}$ Department Of Visceral Surgery, Mohamed V Military Hospital, Hay Ryad 10100 Rabat, Morocco.
}

\begin{abstract}
Background: In the time of the humanitarian crisis, it is possible to see how the Maslow's theory can play a role in determining the different needs of individuals living in refugee camps. Our purpose is to provide an improved approach to structuring needs of refugees by using Maslow's schema.

Methods: We conducted a quantitative study among Syrian refugees consulting in Moroccan Field Hospital in Za'atari camp between august and September 2013. Data were obtained by using a questionnaire created by integrating Maslow's hierarchy of needs and a principal components factor analysis was conducted.

Results: 300 adults were included. The average age of the participants was $26.3 \pm 8.6$ years. A principal components factor analysis identified three factors, titled basic, sentimental and psychosocial needs, which together account for approximately $80.8 \%$ of the variance.
\end{abstract}

Discussion: The findings show the interest of using the Maslow's Hierarchy Needs for preparing and managing a refugee camp.

Keywords: Refugees; Maslow needs; principal components analysis; Moroccan field hospital.

\section{Background}

Although the worldwide establishment of refugee camps has led to a considerable progress in the management of refugees, there has been no widely accepted psychological theory for assessment and designing of response to refugee needs. Often in emergency settings, strong emphasis is placed on food, shelter and water as well as the security of the refugees. Many times the interventions stop here in the belief that once the basic needs have been met the refugees can get on with determining their own lives. The Rwandan genocide in 1994 and the humanitarian community's subsequent failure to meet the needs of displaced persons was a turning point that prompted new discussions to address human rights issues in humanitarian responses. Thereby, the Sphere Project was launched in 1997 to address these concerns and resulted in the Humanitarian Charter and Minimum Standards in Disaster Response, which has since been widely adopted [1].

During last decade, the nature of war and populations affected by conflict has changed, posing new challenges to the international community. Moreover, the frequency, scope and complexity of humanitarian emergencies have increased as have the number of people affected by conflict [2]. The Balkans and Caucus wars of the 1990s and the present day conflict in Syria differ substantially from complex emergencies in lessdeveloped countries, where younger populations are displaced into camp settings and face greater threats of mortality due to infectious disease and acute malnutrition [3]. Today the majority of refugees worldwide are in urban environments, as compared to camps, which necessitates a different type of response from host governments and international organizations [4].

Maslow's model had an immense influence on the field of psychology, including the subfields of personality, social psychology, psychopathology, developmental psychology, and organizational behavior, and it continues to be cited widely in medical papers [8 - 9]. Indeed, the powerful visual image of a pyramid of needs (see Fig. 1) has been one of the most cognitively contagious ideas in the behavioral sciences.

Within humanitarian interventions, it is possible to see how this approach can played a role in determining the different needs of individuals living in the refugee camps. In applying the pyramid to refugees, 
we are not arguing that the hierarchy is universal (applying to all) or rigid where no higher level needs can be addressed until all of the lower ones are first satisfied.

Our purpose is to propose an approach to meet the needs of refugees by using Maslow's schema.

\section{Methods}

\section{Participants}

It is a cross-sectional study including Syrian refugees living in $\mathrm{Al} \mathrm{Za}$ 'atari camp. The sample was constituted by a systematic sampling. The sampling frame corresponded to Syrian refugees adults (age>18years) who visited the Moroccan field hospital between August and September 2013. Data were obtained for each refugee adult (age>18years) regardless of gender or education level. We have excluded from this study refugees who need emergency care and who have spent less than one month in the camp.

\section{Data Collection}

Three Syrian nurses were recruited and trained by the Moroccan epidemiologist on the survey instrument and its implementation. A training workshop prior to the fieldwork focused on sampling procedures, interviewing skills, editing and administrative issues. In order to improve representation, Investigators were assigned in the registration unit at different times of the day, on both weekends and weekdays.

\section{Measures}

An assessment questionnaire was created by integrating Maslow's hierarchy of needs and their items. It was drafted in Arabic and adapted after field-testing. The final draft consisted of six sections: (1) Demographic and displacement history (7 questions covering age, gender, marital status, health status, education, length of stay in the camp, and family size ), (2) Physiological needs (5 questions pertaining to food, water, sex, sleep and homeostasis), (3) Safety needs (5 questions covering data on security of body, resources, the family, health and property), (4) Belonging needs (3 questions covering friendship, family and sexual intimacy), (5) Esteem (2 items covering self-esteem and respect by others) and (6) Self - actualization (problem solving).

A Likert scale was used for responses, with 4 as highly important, 3 as moderately important, 2 as slightly important, and 1 as not important.

\section{Ethical considerations}

Prior to each interview, the research team introduced themselves, explained the objectives of the study, and obtained the respondent's consent for the interview. If the refugee agreed, the informed consent process took place, and the questionnaire was self - administered by the investigators.

\section{Analysis}

A database was constructed using SPSS ${ }^{\circledR}$ PASW Statistics 18, and descriptive analysis were run as appropriate. The composite variables scale corresponding to each need was obtained by averaging the nonmissing values of the items making up that variable. Differences were estimated using chi-square tests for categorical variables and a principal components factor analysis was conducted on the 17 items of the Maslow's pyramid of needs. Principal axis factor analysis with varimax rotation was conducted to assess the underlying structure for the items on the survey.

\section{Participant's characteristics}

\section{Results}

A total of 300 adults from variant ages, genders, education background participated to the study. The average age of the participants was 26.3 years ( $\mathrm{SD}=8.6$, ranged from 18 to 50 years). Of those who responded, $54.7 \%$ were women and $45.3 \%$ were men. $78.4 \%$ of participants had a primary or secondary level and $14.0 \%$ were war wounded. The mean of length of residence in the camp was 210.6 days ( $\mathrm{SD}=57.6$, ranged from 109 to 368 days) and $79 \%$ of refugees were in the camp for more than 6 months. $48 \%$ of families can be considered as "large families" having six or more members.

The means on importance of different needs for refugees ranged from 3.0 to 3.4. This suggests that respondents (Table 1) rated Needs for belonging, needs for esteem and Needs for self-actualization as moderately to highly important.

Regarding participants' scores on the self-report scales as reported in Table 2, average food and water needs on the physiological needs scale were high, generally ranged from 3.1 to 3.4 ("moderately important"). The highest scores for safety needs were recorded for the security of the body (average 3.1; SD 1.2), while the lowest score was found for the security of property (1.4; SD 0.9). With regard to Needs for belonging, higher score were obtained for family relationship (average 3.3; SD 0.9). In terms of need of esteem, the need of "respect by others" (average 3.4; SD 0.5) and "self-esteem" (average 3.5; SD 0.6) scale yielded the highest 
scores. Very high scores were obtained for needs for "self-actualization as reported by Syrian refugees (average 3.4; SD 0.9). Regarding the relationships between the variables under study, the chi-square test revealed few statistically significant differences between different needs and five variables as gender, education level, family size, healthy state and length of stay in the camp as illustrated in Table 3.

Males had higher scores than females for the needs "safety" $(p<0.001)$ and "for belonging" $(p=0.001)$; no other gender differences were found. As a function of education level and healthy state, statistically significant differences were found in the physiological needs and needs for esteem $(\mathrm{p}<0.05)$. Finally, both high education level and length of stay more than 6 months reported significantly higher levels of needs of self actualization.

\section{Needs hierarchy}

A principal components factor analysis with varimax rotation was conducted to assess the underlying structure for the items on the survey. The eigenvalues (>1.0) support that the items can be reduced to 7 factors. However, examination of the screen plot suggests that after the first three components, differences between the eigenvalues decline substantially (Figure 2). These three factors, represented by Figure 3, account together for approximately $80.8 \%$ of the variance as illustrated by Table 4 .

The most commonly needs cited "important" for refugees were titled basic needs including physiological and safety needs as seen in Table 5 . This was followed by psychosocial needs including selfesteem and self-actualization needs. Sentimental needs including love and belonging needs were reported as the last needs.

\section{Discussion}

In general, the Maslow's theory seems to be largely correct and useful for exploring refugee camp needs despite the critics and its limitations. Traditionally, primary responses to forced migration in times of civil war or natural disaster focus on emergency (humanitarian) needs, and the management of communicable diseases. As the drivers of forced migration shift to on-going political crises and instability, associated responses must also change gear in order to follow the evolution of different refugee needs [12].

The survey was limited by the difficulty in selecting a random sample. For security considerations, sample was obtained among refugees visiting Moroccan field hospital. Although efforts were made to obtain a representative sample of the refugee in the zaatari camp, it is possible that sampling missed certain population sub-groups, which may have been different than those that were included which creates the potential for sampling bias.

In this study, gender plays a role in differentiating subgroups of needs. However, males display greater concern than females about needs of safety and for belonging. This finding is in line with cultural perceptions of gender in Arabic family like the Occupied Palestinian Territories [13].

Family size more than six members were statistically associated with almost needs and $52 \%$ of families can be considered "large families" having six or more members. This was higher than the proportion reported in Bengali refugees of Dhaka where Molla found only $24 \%$ of "large families' and the average of family size were 7 [14]. The definition of a family in emergencies such as this differs from the traditional definition of the nuclear family in normal situations. The difference is that extended family members and relatives are living together rather than the stereotypical mother-father-children household. Lastly, higher level of education and length of stay in the camp more than 6 months were highly significant $(p<0.001)$ among the refugees looking for Needs for Esteem and Needs for Self-actualization.

Based our results, physiologic needs and safety needs were the most important aspect of overall refugee needs. Those basic needs were estimated to be slightly important for more than $80 \%$ of refugees and account for approximately $33.5 \%$ of the variance of refugee needs. This is quite less than what adults (in normal situation) were reported by Saeednia [15].

Such as the Maslow's Hierarchy of Needs, Basic Needs constitutes the basis for the pyramid's refugee needs and they should be met in the first days of sheltering in the camp. This study suggests that new arrivals have higher importance for basic needs than former resident does. That is why the first responses should emphasize on basic needs and should be deployed during the first hours of camp setup.

Generally, researchers report that well-being is low when basic needs are not met, and that people who live exposed to threats, such as natural disasters or violence, experience low levels of well-being [16]. Furthermore, some refugees in Rhino Camp in Uganda stated that in order to feel well they would need health and health facilities, and non-food items like pots, blankets and jelly cans [17].

In this context, the $\mathrm{Al} \mathrm{Za}$ 'atari camp authorities have tolerated the installation of markets and the development of commercial activities in the camp (e.g., barbershop, bakers, restaurant, grocery stores...). This had a positive impact, creates a sense of economic security among thousands of refugees, and explains why this 
level is more likely to be found for refugees because they generally have a greater need to feel safe especially during the first days of their arrival in the camp.

The Psychosocial needs dimension, which was used to assess the esteem and self-actualization needs, was ranked second by respondents. For many years, psychosocial support to refugees and internally displaced people was viewed through the lens of Maslowian psychology as a second-tier operation, something to be done after one had met people's basic survival needs in an emergency [22]. More than any other single event, the December 2004 tsunami in Indonesia showed that the psychosocial effects of catastrophic events are not secondary but primary dimensions of the lived experience of emergencies [23]. For a child who had hoped for a good life but who in a matter of minutes lost his home, family, village, belongings, and many friends, the psychosocial shocks were not secondary to his material losses or things to be dealt with later. This brief but catastrophic moment convinced the world that psychosocial support ought to occur at the same time one applies the immediate life-saving measures in areas such as health, water and sanitation, shelter, and food aid.

Maslow states that the "hierarchies are interrelated rather than sharply separated" [24]. This means that esteem and the subsequent levels (self-actualization) are not strictly separated; instead, the levels are closely related. In our study, these two needs (Esteem and Self-actualization) are interrelated and constitute a single dimension and they were highly important to moderately important for more than $80 \%$ of refugees. They represent the second level of refugee needs with approximately $25 \%$ of total variance of those needs.

Low self-esteem or an inferiority complex may result from imbalances during this level in the hierarchy. Refugees with low self-esteem often need respect from others; they may feel the need to seek fame or glory. However, psychological imbalances such as depression can hinder the person from obtaining a higher level of self-esteem or self-respect. This finding was underlined by Y. Tanka and all [25] in his survey reported that self-confidence of Congolese refuges, recruited as health information team (HIT), grew by doing the work and used their own health initiatives which resulted in a growth of self-confidence Furthermore, positive peer relationships have been associated with greater self-esteem and social adjustment among refugee children [26]. Most refugees have a need for stable self-respect and self-esteem. Maslow classified esteem needs into two related sets; one consisting of desires for strength, achievement, and mastery (which contributed to one's selfesteem) and the other consisting of desires for reputation, status, dominance, and glory (or the esteem of others) [27].

In our survey, the findings state that the need for self-esteem and self-actualization is as strong as the physiological and safety needs and refugees must be engaged in a profession or hobby to gain recognition. These activities give the person a sense of contribution or value.

Syrian refugees remaining deeply involved in the Za'atari camp affairs are searching for self-esteem or Self-actualization with the respect and the admiration of others. They are hired as health leaders, security guards, involved in maintenance of order....... They accept such responsibilities voluntarily and not for salaries but to feel that they are useful and earn the esteem and appreciation of others.

After basic needs, Esteem and Self-actualization are fulfilled; the third level of refugee needs is interpersonal and involves feelings of belongingness. These social motivations differ from physiological and safety needs in that they are not necessary for personal survival. However, human beings are exquisitely sensitive to cues of social rejection, and they respond to such cues using some of the same neural circuits used to register physical pain [28].

This study indicates that this need is not very important for adult refugees and explains approximately $24 \%$ of total variance but Community belonging was a particularly strong need of refugees with a disability (sick or war-wounded refugees) and with higher level of education. However, Ignacio and all [30] report in his study that for young people with refugee backgrounds, establishing a sense of belonging to their family and community, and to their country of resettlement is essential for wellbeing in the first three years in Australia. Deficiencies within this level of Maslow's hierarchy due to neglect can impact the individual's ability to form and maintain emotionally significant relationships in general, such as friendship, intimacy and family.

According to Maslow, humans need to feel a sense of belonging and acceptance among their social groups, regardless if these groups are large or small. Many people become susceptible to loneliness, social anxiety, and clinical depression in the absence of this love or belonging element. This need for belonging may overcome the physiological and security needs, depending on the strength of the peer pressure.

So why it is necessary to encourage and support the celebration of social events such as wedding, birth; religious holidays comprised an opportunity of family meeting. In addition, green spaces for meeting and for sport must be developed. These findings support previous work that showed that For Palestinian refugees, a large part of wellbeing is accounted for by the dimensions of friends and family [32]. Furthermore, in Moroccan Field Hospital, we noticed that many patients prefer to discuss with other refugees for several hours in waiting area and leave the hospital without even seeing the doctor. The majority has lost someone and the impact of this experience is very significant. They are frustrated; they feel anxiety so they need people to listen to them. We have seen that when we give more time to patients, their mood will change. 


\section{New Contribution to the Literature}

Our study shows the interest of using the Maslow's Hierarchy Needs for preparing and managing a refugee camp. According to Maslow's Hierarchy Needs, refugees will meet basic physiological and safety needs first. This means that for refugees, who are forced to leave their country and live in neighboring countries; finding basic needs becomes either a key milestone or obstacle in the process of housing step in refugee camp. After this step, camp officials should reflect and prepare other needs according to Maslow's Hierarchy Needs. Providing access to these needs and other resources may help refugees to be better able to live in the camp for a long duration.

\section{Competing interests}

The authors declare no conflict of interest.

\section{Authors' contributions}

All authors contributed equally to this work.

\section{Tables and figures}

Table 1. Percentages of Respondents "importance of needs in the refugee camp" ( $\mathrm{n}=300$, Za'atari camp, 2013)

Table 2. Total Variance Explained for composite factors

Table 3: Comparison of different needs declared by Syrian refugees as Moderately to Highly important (zaatari camp 2013)

Table 4. Total Variance Explained for composite factors

Table 5 : Rotated Component Matrix for composite factors

Figure 1: An interpretation of Maslow's hierarchy of needs, represented as a pyramid with the more basic needs at the bottom

Figure 2: Scree plot.

Figure 3. Component plot in rotated space for composite factors (Za'atari camp, 2013)

Figure 4: Maslow's pyramid of needs adapted for Syrian refugees

\section{References}

[1]. SPHERE 2004 : The Sphere Project. (2004). Humanitarian charter and minimum standards in disaster response. URL. http://www.sphereproject.org/ (accessed November, 2013).

[2]. Maxwell, D., Webb, P., Coates, J., \& Wirth, J. (2010). Fit for purpose? Rethinking food security responses in protracted humanitarian crises. Food Policy, 35, 91 - 97.

[3]. Salama, P., Spiegel, P., Talley, L., \& Waldman, R. (2004). Lessons learned from complex emergencies over the past decade. Lancet, 364, 1801 - 1813.

[4]. Spiegel, P., Checchi, F., Colombo, S., \& Palk, E. (2010). Health-care needs of people affected by conflict: future trends and changing frameworks. Lancet, 375 (9711), $341-345$.

[5]. Hamel S., Leclerc G., Lefrancois, R. (2003). A psychological outlook on the concept of transcendent actualization. The International Journal for the Psychology of Religion, 13(1), 3-15.

[6]. Maslow, AH. A theory of human motivation. Psychological Review, Vol. 50. 1943, 370-396.

[7]. Hoffman, E. The Maslow effect: A humanist legacy for nursing. American Nurse Today, 2008, 3(8), 36-37.

[8]. Taormina RJ, Gao JH. Maslow and the motivation hierarchy: measuring satisfaction of the needs. Am J Psychol. 2013 Summer;126 (2):155-77.

[9]. Douglas T. Kenrick, Vladas Griskevicius, Steven L. Neuberg, and Mark Schaller. Renovating the Pyramid of Needs: Contemporary Extensions Built Upon Ancient Foundations . Perspect Psychol Sci. 2010 May ; 5(3): 292-314

[10]. Diener, E. (2011). Needs and subjective well-being around the world. Journal of Personality and Social Psychology, 101(2), 354365. doi: $10.1037 / \mathrm{a} 0023779$

[11]. Alderfer CP. Existence relatedness and growth. New York: Freepress; 1972.

[12]. Von Schreeb J, Unge C, Brittain-Long R, Rosling H: Are donor allocations for humanitarian health assistance based on needs assessment data? Global Public Health 2008, 3:440.

[13]. Veronese, G., Castiglioni, M., \& Said, M. (2011). Arabic family in transition: The case of Palestinians living in Israel. In G. M. Ruggiero, S. Sassaroli, Y. Latzer, \& S. Suchday (Eds.), Perspectives on immigration and terrorism (pp. 74-84). Amsterdam: IOS.

[14]. Molla, N.A., et al. Quantifying disease burden among climate refugees using multidisciplinary approach: A case of Dhaka, Bangladesh. Urban Climate (2014), http://dx.doi.org/10.1016/j.uclim.2014.02.003

[15]. Yadolla Saeednia, Mariani MD NOR. Measuring Hierarchy of Basic Needs Among Adults. Procedia - Social and Behavioral Sciences 82 (2013) $417-420$.

[16]. Lopez, S.J. et al. (2002) "Putting positive psychology in a multicultural context", in C.R. Snyder and S.J. Lopez (eds) Handbook of Positive Psychology, 700-714, Oxford: University Press.

[17]. UNHCR. Self-image and the well-being of refugees in Rhino Camp, Uganda. http://www.unhcr.org/40b1f63b4.html. (accessed November, 2013).

[18]. International Federation of Red Cross and Red Crescent Societies and the Jordan Red Crescent, Syrian Refugees living in the Community in Jordan - Assessment Report. Amman, Jordan: Jordan Red Crescent; 2012.

[19]. Diener, E. (1994). Assessing subjective well-being: Progress and opportunities. Social Indicators Research, 31, 103-157.

[20]. Hunt H, Gakenyi M. Comparing refugees and nonrefugees : the Bosnian experience/ Anxiety Disorders 19 (2005) 717-723

[21]. Doocy S, Sirois A, Anderson J, Tileva M, Biermann M, Storey JD,Burnham D. Food security and humanitarian assistance among displaced Iraqi populations in Jordan and Syria. Social Science \& Medicine 72 (2011) 273e282 
[22]. Michael G. Wessells Do No Harm: Challenges in Organizing Psychosocial Support to Displaced People in Emergency Settings. Refuge Volume 25 Number 1

[23]. 27. Guha-Sapir D, van Panhuis WG Health impact of the 2004 Andaman Nicobar earthquake and tsunami in Indonesia. Prehosp Disaster Med. 2009 Nov-Dec; 24(6):493-9.

[24]. Maslow, AH. Motivation and personality. 2nd ed.. New York: Harper \& Row; 1970.

[25]. Tanaka Y,Kunii O, Okumura J, Wakai S. Refugee participation in health relief services during the post-emergency phase in Tanzania Public Health (2004) 118, 50-61)

[26]. Lustig, S. L., Kia-Keating, M., Grant Knight,W., Geltman, P., Ellis, H., Kinzie, J. D., et al. (2004). Review of child and adolescent refugee mental health. Journal of the American Academy of Child \& Adolescent Psychiatry, 43(1), 24e36.

[27]. Douglas T. Kenrick, Vladas Griskevicius, Steven L. Neuberg, Mark Schaller. Renovating the Pyramid of Needs: Contemporary Extensions Built Upon Ancient Foundations. Perspect Psychol Sci. 2010 May ; 5(3): 292-314.

[28]. Eisenberger NI, Lieberman MD, Williams KD. Does rejection hurt? An fMRI study of social exclusion. Science. 2003; 302:290292.

[29]. Schaller M, Park JH, Mueller A. Fear of the dark: Interactive effects of beliefs about danger and ambient darkness on ethnic stereotypes. Personality and Social Psychology Bulletin. 2003; 29:637-649.

[30]. Ignacio Correa-Velez, Sandra M. Gifford, Adrian G. Barnett. Longing to belong: Social inclusion and wellbeing among youth with refugee backgrounds in the first three years in Melbourne, Australia . Social Science \& Medicine 71 (2010) 1399e1408.

[31]. Maner JK, DeWall CN, Baumeister RF, Schaller M. Does social exclusion motivate interpersonal reconnection? Resolving the "porcupine problem.”. Journal of Personality and Social Psychology. 2007; 92:42-55.

[32]. Guido Veronese, Marco Castiglioni, Gianpiero Barola, Mahmud Life satisfaction and positive emotion as protective factors in a group of Palestinian school children Children and Youth Services Review 34 (2012) 225-233)

Table 1: Percentages of Respondents "importance of needs in the refugee camp" ( $\mathrm{n}=300$, Za'atari camp, 2013)

\begin{tabular}{lcccccccc}
\hline \multirow{2}{*}{ Scores } & \multicolumn{2}{c}{$\begin{array}{c}\text { Highly } \\
\text { important }\end{array}$} & \multicolumn{2}{c}{$\begin{array}{c}\text { Moderately } \\
\text { important }\end{array}$} & \multicolumn{2}{c}{ Slightly important } & \multicolumn{2}{c}{ Not important } \\
\cline { 2 - 10 } & $\mathrm{N}$ & $\%$ & $\mathrm{~N}$ & $\%$ & $\mathrm{~N}$ & $\%$ & $\mathrm{~N}$ & $\%$ \\
\cline { 2 - 10 } Physiologic needs & 0 & $0,0 \%$ & 23 & $7,7 \%$ & 277 & $92,3 \%$ & 0 & $0,0 \%$ \\
Safety needs & 30 & $10,0 \%$ & 29 & $9,7 \%$ & 241 & $80,3 \%$ & 0 & $0,0 \%$ \\
Needs for Belonging & 33 & $11.0 \%$ & 247 & $82,3 \%$ & 20 & $6.7 \%$ & 0 & $0,0 \%$ \\
Needs for Esteem & 278 & $92,7 \%$ & 22 & $7,3 \%$ & 0 & $0,0 \%$ & 0 & $0,0 \%$ \\
Needs for Self-actualzation & 199 & $66,3 \%$ & 42 & $14,0 \%$ & 40 & $13,3 \%$ & 19 & $6,3 \%$ \\
\hline
\end{tabular}

Table 2: Descriptive data of different refugee needs ( Za'atari camp, 2013)

\begin{tabular}{ccccc}
\hline & N & Mean & Median & SD \\
\hline Physiologic needs & & & & \\
Food & 300 & 3,1 & 2,00 & 1,00 \\
Water & 300 & 3,40 & 4,00 & 0,81 \\
Homeostasis & 300 & 2,68 & 3,00 & 1,03 \\
Sex & 216 & 1,31 & 1,00 & 0,79 \\
Sleep & 278 & 1,92 & 2,00 & 0,87 \\
Safety needs & & 3,06 & 4,00 & 1,18 \\
Security of body & 300 & 1,93 & 2,00 & 1,11 \\
Security of resources & 245 & 2,70 & 3,00 & 1,00 \\
Security of family & 290 & 2,43 & 3,00 & 1,10 \\
Health security & 300 & 1,38 & 1,00 & 0,91 \\
Property security & 259 & 2,67 & & \\
Needs for Belonging & & 3,33 & 3,00 & 0,98 \\
Sexual intimacy & 290 & 2,88 & 3,00 & 0,86 \\
Family relationship & 290 & & 3,00 & 0,73 \\
Friendship & 300 & 3,45 & 3,00 & 0,50 \\
Needs for Esteem & & 3,55 & 4,00 & 0,57 \\
Respect by others & 300 & & & \\
Self-esteem & 300 & 3,42 & 4,00 & 0,96 \\
Needs for Self-actualization & & & & \\
Problem solving & 289 & &
\end{tabular}

Table 3: Comparison of different needs declared by Syrian refugees as Moderately to Highly important (zaatari camp 2013)

\begin{tabular}{|c|c|c|c|c|c|c|c|}
\hline & & & $\begin{array}{c}\text { Physiologic } \\
\text { needs }\end{array}$ & $\begin{array}{l}\text { Safety } \\
\text { needs }\end{array}$ & $\begin{array}{l}\text { Needs for } \\
\text { Belonging }\end{array}$ & $\begin{array}{l}\text { Needs for } \\
\text { Esteem }\end{array}$ & $\begin{array}{c}\text { Needs for } \\
\text { Self- } \\
\text { actualization }\end{array}$ \\
\hline \multirow[t]{5}{*}{ Gender } & Male $(n=136)$ & $\mathrm{n}$ & 126 & 114 & 71 & 114 & 104 \\
\hline & & $\%$ & 92.6 & 83.3 & 52.2 & 83.8 & 83.2 \\
\hline & Female $(n=164)$ & $\mathrm{n}$ & 144 & 104 & 107 & 145 & 126 \\
\hline & & $\%$ & 87.8 & 63.4 & 65.2 & 88.4 & 76.8 \\
\hline & $p$-Value & & 0.1 & $<0.001$ & 0.02 & 0.16 & 0.12 \\
\hline High & No $(n=237)$ & $\mathrm{n}$ & 207 & 175 & 222 & 189 & 191 \\
\hline education & & $\%$ & 87.3 & 73.8 & 95.4 & 79.7 & 80.6 \\
\hline \multirow[t]{3}{*}{ level* } & Yes $(n=63)$ & $\mathrm{n}$ & 59 & 43 & 51 & 61 & 59 \\
\hline & & $\%$ & 93.6 & 68.3 & 80.9 & 96.8 & 93.6 \\
\hline & $p$-Value & & 0.16 & 0.23 & 0.001 & 0.001 & 0.02 \\
\hline
\end{tabular}


Exploring Refugee Camp Needs: An Empirical Investigation Of Maslow's Theory In...

\begin{tabular}{|c|c|c|c|c|c|c|c|}
\hline \multirow{3}{*}{$\begin{array}{l}\text { Family } \\
\text { size }\end{array}$} & \multirow{2}{*}{ More than 6 members $(n=144)$} & $\mathrm{n}$ & 134 & 141 & 133 & 103 & 115 \\
\hline & & $\%$ & 93.1 & 97.9 & 92.4 & 71.54 & 79.9 \\
\hline & \multirow[t]{2}{*}{ Less than 6 members $(n=156)$} & $\mathrm{n}$ & 135 & 149 & 106 & 106 & 115 \\
\hline \multirow{6}{*}{ Disability } & & $\%$ & 87.7 & 95.5 & 67.9 & 67.9 & 79.3 \\
\hline & \multirow{3}{*}{$\begin{array}{r}p \text {-Value } \\
\text { Yes }(\mathrm{n}=238)\end{array}$} & & 0.07 & 0.2 & $<0.001$ & 0.5 & 0.5 \\
\hline & & $\mathrm{n}$ & 218 & 164 & 117 & 197 & 176 \\
\hline & & $\%$ & 91.6 & 68.9 & 49.1 & 82.8 & 77.5 \\
\hline & \multirow[t]{2}{*}{ No $(n=62)$} & $\mathrm{n}$ & 52 & 54 & 51 & 59 & 54 \\
\hline & & $\%$ & 83.9 & 87.1 & 82.2 & 93.6 & 87.1 \\
\hline \multirow{6}{*}{$\begin{array}{l}\text { Length of } \\
\text { stay in } \\
\text { the camp }\end{array}$} & $p$-Value & & 0.06 & 0.002 & $<0.001$ & 0.01 & 0.07 \\
\hline & \multirow[t]{2}{*}{ More than 6 months $(\mathrm{n}=237)$} & $\mathrm{n}$ & 197 & 169 & 226 & 206 & 212 \\
\hline & & $\%$ & 82.8 & 71.3 & 95.4 & 86.9 & 89.4 \\
\hline & \multirow[t]{2}{*}{ Less than 6 months $(n=63)$} & $\mathrm{n}$ & 59 & 49 & 63 & 42 & 48 \\
\hline & & $\%$ & 93.6 & 77.8 & 100 & 66.7 & 76.1 \\
\hline & $p$-Value & & 0.01 & 0.2 & 0.07 & 0.0001 & 0.01 \\
\hline
\end{tabular}

*High education level: university education

Table 4. Total Variance Explained for composite factors

\begin{tabular}{ccccccc}
\hline \multirow{2}{*}{ Component } & \multicolumn{3}{c}{ Initial Eigenvalues } & \multicolumn{2}{c}{ Rotation Sums of Squared Loadings } \\
\cline { 2 - 6 } & Total & $\begin{array}{c}\text { \% of } \\
\text { Variance }\end{array}$ & Cumulative \% & Total & $\begin{array}{c}\text { \% of } \\
\text { Variance }\end{array}$ & $\begin{array}{c}\text { Cumulative } \\
\%\end{array}$ \\
\cline { 2 - 6 } 1 & 1,676 & 33,512 & 33,512 & 1,599 & 31,974 & 31,974 \\
2 & 1,227 & 24,531 & 58,042 & 1,245 & 24,897 & 56,871 \\
3 & 1,139 & 22,773 & 80,815 & 1,197 & 23,944 & 80,815 \\
4 &, 756 & 15,113 & 95,928 & & & \\
5 &, 204 & 4,072 & 100,000 & & & \\
\hline
\end{tabular}

Extraction Method: Principal Component Analysis.

Table 5 : Rotated Component Matrix for composite factors

\begin{tabular}{cccc}
\hline & \multicolumn{3}{c}{ Component } \\
\cline { 2 - 4 } & 1 & 2 & 3 \\
\cline { 2 - 4 } Physiologic needs & 0.876 & -0.190 & 0.324 \\
Safety needs & 0.907 & 0.062 & -0.307 \\
Needs for belonging & -0.014 & 0.019 & 0.958 \\
Needs for esteem & -0.001 & 0.794 & 0.204 \\
Needs for self-actualzation & -0.090 & 0.757 & -0.196 \\
\hline
\end{tabular}

Extraction Method: Principal Component Analysis.

Rotation Method: Varimax with Kaiser Normalization.

Figure 1: An interpretation of Maslow's hierarchy of needs, represented as a pyramid with the more basic needs at the bottom

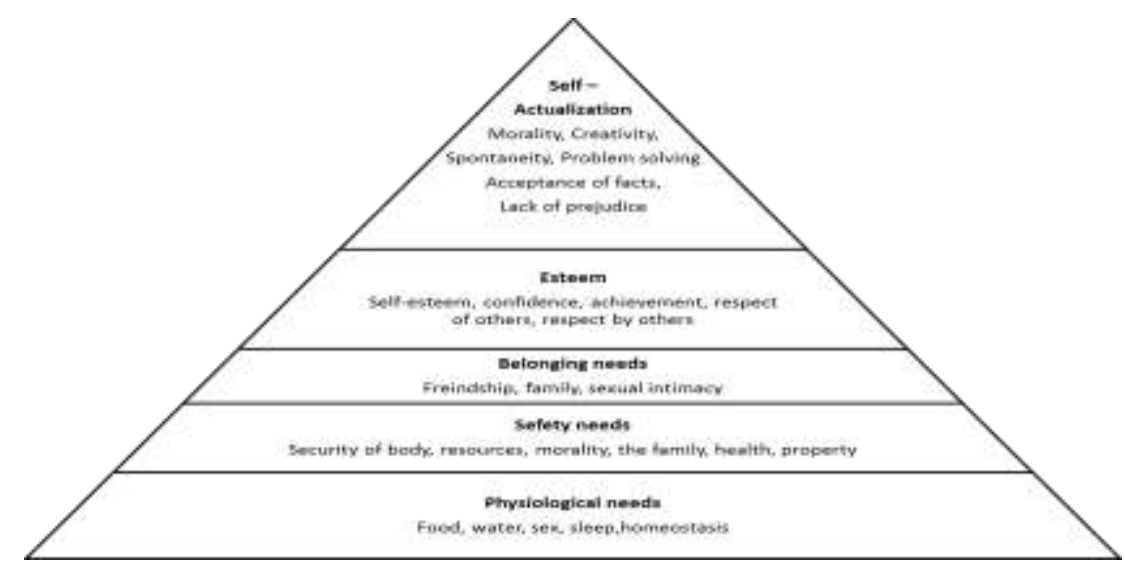

Figure 2: Scree plot. 


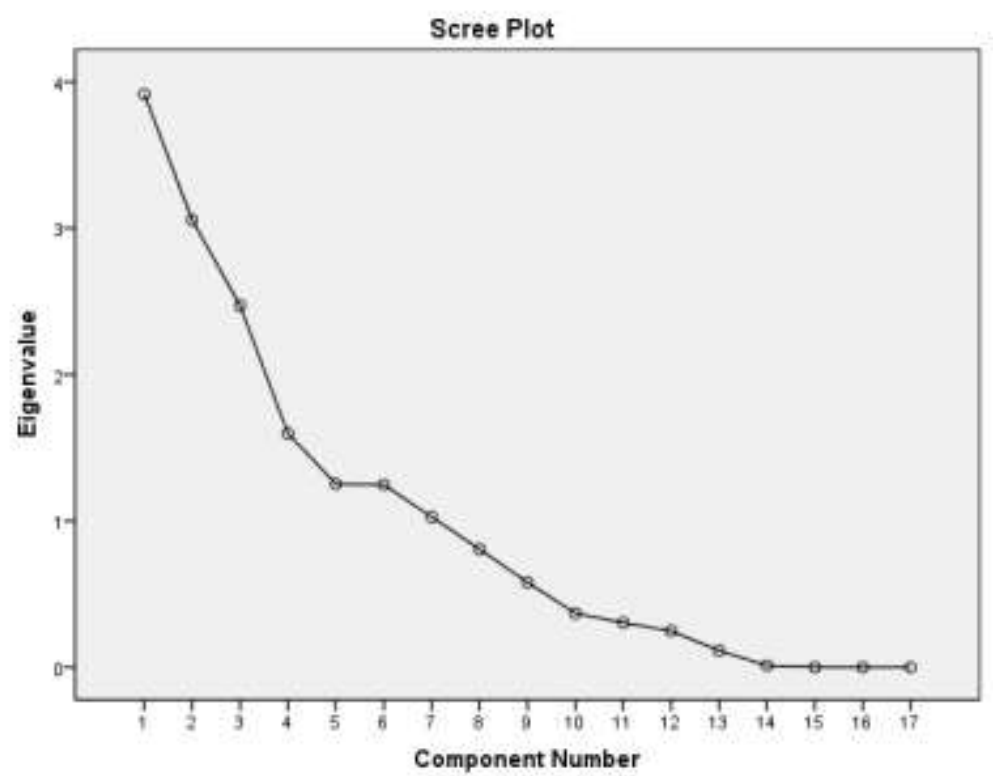

Figure 3. Component plot in rotated space for composite factors (Za'atari camp, 2013)

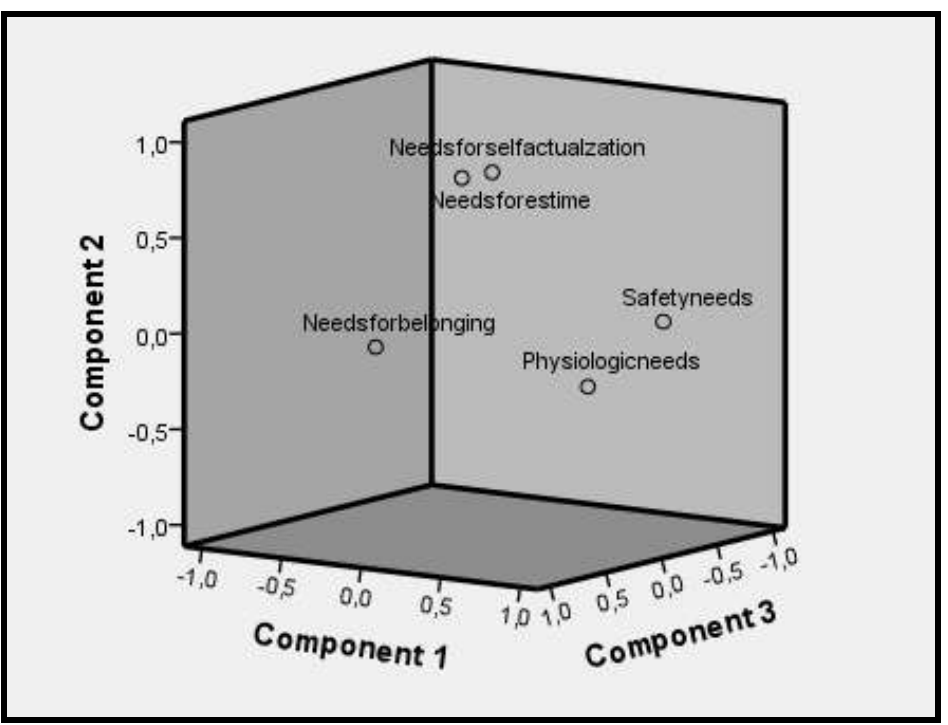

Figure 4: Maslow's pyramid of needs adapted for Syrian refugees

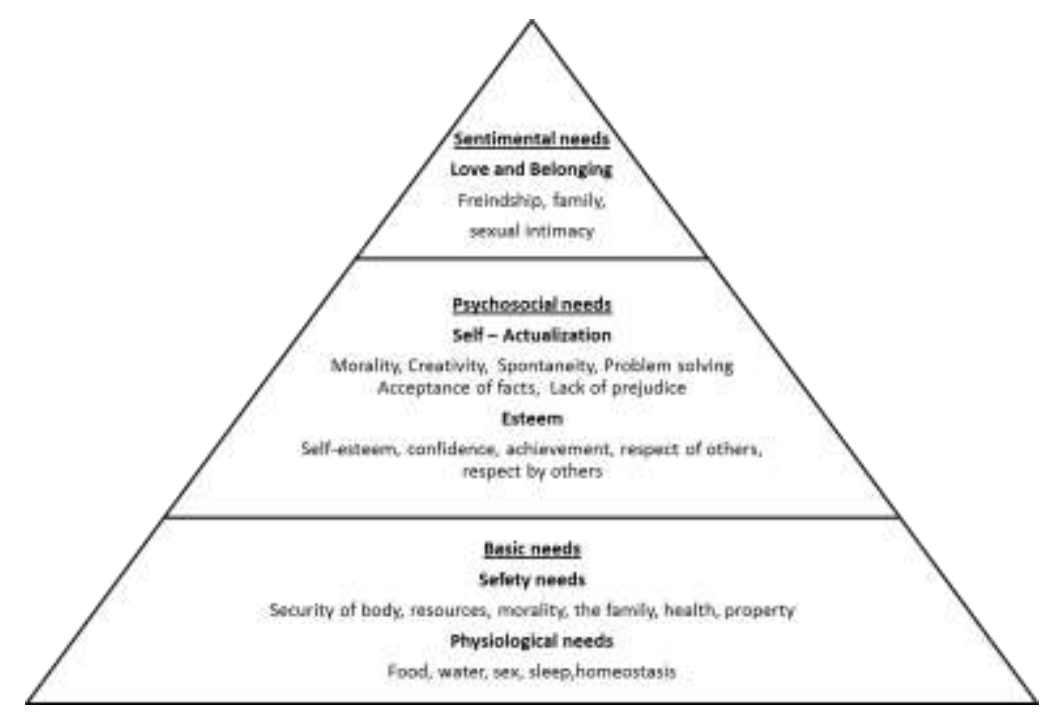

